\title{
Influence of physical activity on students' life quality
}

\author{
Leifa A.V. ${ }^{1}$, Zheleznyak Y.D. ${ }^{2}$ \\ ${ }^{1}$ Amur State University, Blagoveshchensk, Russia \\ ${ }^{2}$ Moscow State Regional University, Moscow, Russia
}

\begin{abstract}
Purpose: $\quad$ influence of students' targeted and regular physical activity on their life quality.

Material: $\quad$ in the research students $(n=325$, age 18-21 years) participated. Students' life quality was studied with the help of questionnaire "MOS SF-36» (J.E.Ware). We determined students' physical workability and physical fitness.

Results: $\quad$ formation of students' physical activity was based on the worked out technology: 1) motor functioning for general endurance; 2) accent on speed-power training was made in second half of semester; 3 ) training of dexterity and flexibility was realized considering certain kind of academic material and future professional activity; 4) the structure of trainings in academic year included 3 stages. At first stage (September, October) $70 \%$ of time was spent for endurance, $15 \%$ - for quickness and 15\% for strength. At second stage (November, March) $50 \%$ was assigned for endurance, $30 \%$ - for quickness and $20 \%$ - for strength. At third stage (April, May) $40 \%$ of time was assigned for quickness, $40 \%$ - for strength and 30\% - for endurance. As a result of realization of the worked out technology for students' physical activity their individual health improved and became the factor of students' life quality perfection.

Conclusions: targeted and regular physical activity of students confidently influences on their individual health by all indicators: organism's functional reserves; physical workability and fitness, way of life and organism's resistance. Targeted and regular physical activity of students facilitates improvement of students' life quality.

Keywords: activity, physical, health, life quality, students.
\end{abstract}

\section{Introduction}

In period of any society's gradual development humanistic values and rising of life qualities are very important. Life quality of man to large extent is determined by human physical activity and health. In new conditions of development of Russia social component of physical activity in society increases and its role in formation of healthy life style and quality increase.

Students are main subject of educational process in HEE. In "Strategy of state youth policy in Russian Federation to 2016" youth's quality id defined as resulting systemic indicator of youth policy's effectiveness and its interconnection with development of country. Improvement of youth's life quality and development of country are defined as strategic task [1]. All efforts of science and education shall be directed at improvement of life quality. In this aspect higher educational establishments' students' are themselves interested in rising of their life quality, from position of active life, receiving good professional education, reaching proper professional fitness and so on.

Great number of scientific works is devoted to human physical activity. Physical activity is understood as targeted and regular motor functioning. This functioning is directed at improvement of physical condition, functional state and health. In this process motor functioning plays important role [2].

V.K. Balsevich thought that the most substantial manifestation of personality's physical culture is physical activity as special form of human functioning [3]. N.I. Ponomariov says that human physical activity contains a system of ideas about main laws of controlled development of human potential; ways and means of personality's active attitude to physical perfection; its forms and organization [4].

Thus, students' physical activity we understand as students' targeted and regular motor functioning, directed (c) Leifa A.V., Zheleznyak Y.D., 2017 doi:10.15561/20755279.2017.0507 at their physical condition's improvement as well as organism's functional stateT and health [5].

Reduction of human physical activity, with simultaneous increase of nervous emotional tension, results in health worsening [6]. Such tendency is relevant both for adult and young population of Russia [7].

The work of N.V. Sokolova is devoted to study of hygienic factors' role in formation of girl pedagogic HEE students' life quality [8]. In work of S.I. Kartysheva there is analysis of formation of boy students' life quality. The author found that formation of students' life quality is influenced by such factors as: health, material conditions. Correct eating; high personal anxiety; relations in academic group; behavior risk factors [9]. The problem of students' life quality were continued by N.V. Mukhina. She studied gender peculiarities of formation of students' life quality and dynamic of studying in pedagogic HEE [10].

Recent years in scientific literature there have been appeared the works on physical culture means usage for rising human life qualities. Ye.V. Tokar and A.M. Koechevskiy regarded factors influencing on life quality of higher education establishments' teachers [11]. In their research they showed that main factor was physical activity of teachers. I.V. Samsonenko showed positive influence of athletic gymnastic and information technologies on quality of students' life [12].

Formation of students' positive attitude to own health is influenced by the following: optimal physical loads $[13,14]$; application of modern and attractive training forms $[15,16]$; individual approach to training [17]; physical fitness [18]; possibility to choose kind of sports in compliance with own abilities [19, 20].

V.A. Orynchuk found interactions between physical, psychic and social components of student's life quality and his/her way of life, educational medium of HEE [21]. I.A. Sviridova assessed system of vocational training and students' medical aid organization. Such system 
socially determines students' health and raise life quality of Kemerovskaya region students [22]. Social principles of students' physical activity's formation and life quality rising are also regarded in other works $[23,24]$.

A number of foreign works was devoted to indicators of health and life quality: attributes and criteria of assessment [25]. In the study of Harris J. physical culture education of students, propaganda of healthy and active way of life was regarded [26]. In opinion of many authors life quality is subjective assessment of satisfaction with different aspects of life; the felt life quality, subjective feelings of individual, formed on the base of certain life conditions and emotional state [27]. Life quality can be regarded from the following positions: healthy way of life in regress of sub-optimal health state [28]; volume and social context of physical activity [29]; importance of physical activity and sleep [30]; control of physical load [31,32]; satisfaction with trainings' organization [33].

Thus, students' life quality is understood by us as system of life values, which characterize the following: students' educational and future professional activity; satisfaction of demands; personal development in aspect of satisfaction with life, social relations and surrounding, educational and personal medium. Great importance in its increasing has health, healthy life style, targeted and regular physical activity [12]. Conception "system" in definition of life quality shows that main method of assessment and study of life quality components are systemic analysis, combination of scientific methods and practical techniques of the problem's solution on the base of systemic approach and regarding the object of the research as a system.

The purpose of the research is substantiation of physical activity's technologies in higher educational establishment and their influence on students' life quality.

\section{Material and methods}

Participants: students of Amur State University, ( $\mathrm{n}=325$, возраст 18-21 год).

Assessment of students' individual health was based on approach of V.I. Bielov [34], which permits to assess main systems of organism's life provisioning (cardio-vascular, respiratory), physical condition, physical workability, way of life. Such methodic was supplemented by us by a number of informative indicators, permitting to assess physical workability and physical fitness. Health ranging was fulfilled by 4 levels.

Students' life quality was assessed with the help of questionnaire "MOS SF-36» (Russian version of J.E.Ware,1992) [35].

Organization of the research

Pedagogic experiment was built on the base of longitudinal research, starting from first year and up to the forth, inclusive (2012-2013 -2015-2016 academic years). As a result technology of students' physical activity was worked out, which included:

1. Motor activity was directed at increase of general endurance at the account of volume and intensity of load. Trainings for endurance were concentrated by us at the beginning of academic year during 1,5-2 months before starting of "geographic zone" (in Far East it is beginning of November) and were conducted in the fresh air. It increased resistance of organism to unfavorable climatic conditions. The achieved general endurance sustained during all academic year with aerobic cyclic exercises.

2. Accent on speed power training was made in second half of every semester. It included physical exercises with weights, different jumps, games in the fresh year and relay races.

3. Training of dexterity and flexibility was realized as per academic material, considering future professional activity.

4. The structure of trainings in academic year consisted of three stages. At first stage (September, October) $70 \%$ of time was devoted to training of endurance, $15 \%$ - quickness and $15 \%$ - strength. We used uniform method and different variants of alternative method. At second stage (November, March) $-50 \%$ were assigned for endurance, $30 \%$ - for quickness and $20 \%$ - for strength. We used uniform, alternative, repeated, interval and competition training methods. At third stage (April, May) $40 \%$ of time was spent for quickness, $40 \%$ - for strength and $30 \%$ - for endurance. Repeated, interval and competition training methods were used.

\section{Statistical analysis}

Student's t-test was found by table of bordering values at confident level $95,99,99,9 \%$ of null hypothesis probability and number of degrees of freedom $\mathrm{f}=\mathrm{n}-1$.

For determination of confidence of differences between mean values of compared parameters we used pair and not pair criterion $t$ as well as non parametric criterion U (Wilcoxon-Manna-Whitney). When using not pair criterion the number of freedom degrees was found as $\mathrm{f}=\mathrm{n}_{1}+\mathrm{n}_{2}-2$, for pair $-\mathrm{f}=2 \mathrm{n}-1$. We considered significance levels of differences (p) 0,$05 ; 0,01 ; 0,001$. Differences considered to be confident at $p<0,05$.

With the help of computer program Deductor (Base Group) [36] we simulated indicators of physical condition: determined significance of a number of factors' influence on final result and prediction.

\section{Results}

Results of the researches showed that by all indicators there happened confident changes (at $p<0,05$ ) (See table $1)$.

In the process of experiment integral indicator confidently changed from $2,7 \pm 0,28$ points in first year $\left(2^{\text {nd }}\right.$ level) to $4,3 \pm 0,34$ in forth year ( $4^{\text {th }}$ level). Indicators of functional reserves confidently increased from $2,9 \pm 0,44$ points in first year to $4,4 \pm 0,42$ - in forth. Physical workability and physical fitness indicators increased from $2,4 \pm 0,22$ and $2,7 \pm 0,32$ points in first year ( $\left.2^{\text {nd }} l e v e l\right)$ to $4,4 \pm 0,22$ and $4,6 \pm 0,38$ points in forth ( $4^{\text {th }}$ level). In forth year we observed a tendency to insignificant reduction of physical fitness indicators. It can be connected with insignificant weakening of physical activity. Indicators of students' way of life and organism's resistance (by frequency of diseases per year) changed, during 
experiment, from $2,7 \pm 0,21$ and $2,9 \pm 0,24$ points in first year ( $2^{\text {nd }}$ level) to $4,3 \pm 0,24$ - in forth year $\left(3^{\text {rd }}\right.$ level and $4^{\text {th }}$ levels).

Results of study of experimental group students' life quality (see table 2) show that in first and second years physical and psychic components of life quality are at low level ( $47 \pm 4,3$ points), at ( $\mathrm{p}<0,05)$.

Low indicators of physical components show that physical state restricts fulfillment of physical loads and physical activity. It influences on state of health. Low indicators of psychic component witness about presence of depressive, troublesome feelings, psychic troubles. In second year we also observed low (close to average) level of students' life quality $(60 \pm 6,3$ points, $\mathrm{p}<0,05)$. Results of our research show that third year students have average and above average levels of life quality $(73 \pm 6,4$ points, $\mathrm{p}<0,05)$. Forth year has the highest indicators of life quality $(89 \pm 7,4$ points, $\mathrm{p}<0,05)$. Students of this group are well adapted to university conditions. They have high physical and life activity and low anxiety.

Table 1.Dynamic of changes of students' individual health in points

\begin{tabular}{|c|c|c|c|c|c|}
\hline Indicators & Group & $\begin{array}{l}1 \text { year } \\
M \pm m\end{array}$ & $\begin{array}{l}2 \text { year } \\
\mathbf{M} \pm \mathbf{m}\end{array}$ & $\begin{array}{l}3 \text { year } \\
M \pm m\end{array}$ & $\begin{array}{l}4 \text { year } \\
M \pm m\end{array}$ \\
\hline Functional reserves of organism & $\begin{array}{l}\text { EG CG } \\
p\end{array}$ & $\begin{array}{l}2,9 \pm 0,44 \\
3,0 \pm 0,40 \\
>0,05\end{array}$ & $\begin{array}{l}3,0 \pm 0,42 \\
3,1 \pm 0,44 \\
>0,05\end{array}$ & $\begin{array}{l}3,7 \pm 0,33 \\
3,5 \pm 0,38 \\
>0,05\end{array}$ & $\begin{array}{l}4,4 \pm 0,42 \\
3,5 \pm 0,38 \\
<0,05\end{array}$ \\
\hline Physical workability & $\begin{array}{l}\text { EG CG } \\
\mathrm{p}\end{array}$ & $\begin{array}{l}2,4 \pm 0,22 \\
2,5 \pm 0,26 \\
>0,05\end{array}$ & $\begin{array}{l}3,4 \pm 0,34 \\
3,3 \pm 0,32 \\
>0,05\end{array}$ & $\begin{array}{l}3,7 \pm 0,26 \\
3,4 \pm 0,30 \\
>0,05\end{array}$ & $\begin{array}{l}4,6 \pm 0,38 \\
3,4 \pm 0,22 \\
<0,05\end{array}$ \\
\hline Physical fitness & $\begin{array}{l}\text { EG CG } \\
p\end{array}$ & $\begin{array}{l}2,7 \pm 0,32 \\
2,7 \pm 0,26 \\
>0,05\end{array}$ & $\begin{array}{l}3,4 \pm 0,35 \\
3,3 \pm 0,30 \\
>0,05\end{array}$ & $\begin{array}{l}3,9 \pm 0,41 \\
3,6 \pm 0,36 \\
>0,05\end{array}$ & $\begin{array}{l}4,5 \pm 0,42 \\
3,6 \pm 0,40 \\
<0,05\end{array}$ \\
\hline Way of life & $\begin{array}{l}\text { EG CG } \\
p\end{array}$ & $\begin{array}{l}2,7 \pm 0,21 \\
2,6 \pm 0,20 \\
>0,05\end{array}$ & $\begin{array}{l}3,2 \pm 0,21 \\
3,1 \pm 0,18 \\
>0,05\end{array}$ & $\begin{array}{l}3,3 \pm 0,24 \\
3,4 \pm 0,22 \\
>0,05\end{array}$ & $\begin{array}{l}4,0 \pm 0,38 \\
3,6 \pm 0,20 \\
<0,05\end{array}$ \\
\hline Resistance of organism & $\begin{array}{l}\text { EG CG } \\
p\end{array}$ & $\begin{array}{l}2,9 \pm 0,24 \\
2,9 \pm 0,22 \\
>0,05\end{array}$ & $\begin{array}{l}3,3 \pm 0,19 \\
3,3 \pm 0,20 \\
>0,05\end{array}$ & $\begin{array}{l}3,7 \pm 0,21 \\
3,5 \pm 0,24 \\
>0,05\end{array}$ & $\begin{array}{l}4,3 \pm 0,24 \\
3,5 \pm 0,23 \\
<0,05\end{array}$ \\
\hline Integral indicator & $\begin{array}{l}\text { EG CG } \\
p\end{array}$ & $\begin{array}{l}2,7 \pm 0,28 \\
2,7 \pm 0,26 \\
>0,05\end{array}$ & $\begin{array}{l}3,3 \pm 0,30 \\
3,2 \pm 0,29 \\
>0,05\end{array}$ & $\begin{array}{l}3,7 \pm 0,29 \\
3,5 \pm 0,28 \\
>0,05\end{array}$ & $\begin{array}{l}4,3 \pm 0,34 \\
3,5 \pm 0,27 \\
<0,05\end{array}$ \\
\hline Level & EG CG & $\begin{array}{l}\text { II (crit.) } \\
\text { II (crit.) }\end{array}$ & $\begin{array}{l}\text { II (crit.) } \\
\text { II (crit.) }\end{array}$ & $\begin{array}{l}\text { III (adm) } \\
\text { III(adm) }\end{array}$ & $\begin{array}{l}\text { IV (proper) } \\
\text { III (adm.) }\end{array}$ \\
\hline
\end{tabular}

Notes: EG - experimental group; CG-control group; Level of significance (p) was 0,05 and $t>t$ cr. Of deviation $H_{0,} t$ $<\mathrm{t}$ cr. Not deviation $\mathrm{H}_{0}$; crit - critical level. Adm - admissible level; proper - proper level; $\mathrm{M}$ - mean arithmetic; $\mathrm{m}$ standard error of mean arithmetic.

Table 2. Change of students' life quality

\begin{tabular}{|c|c|c|c|c|c|}
\hline Components & $\begin{array}{l}1 \text { year } \\
x \pm m\end{array}$ & $\begin{array}{l}2 \text { year } \\
x \pm m\end{array}$ & $\begin{array}{l}3 \text { year } \\
\mathbf{x} \pm m\end{array}$ & $\begin{array}{l}4 \text { year } \\
x \pm m\end{array}$ & $\mathbf{p}$ \\
\hline Physical component of health, points & $48 \pm 5,3$ & $58 \pm 4,7$ & $75 \pm 7,2$ & $84 \pm 8,1$ & $<0,05$ \\
\hline Physical functioning, points & $45 \pm 5,1$ & $50 \pm 4,1$ & $77 \pm 7,2$ & $83 \pm 6,0$ & $<0,05$ \\
\hline Role functioning, points & $46 \pm 4,9$ & $56 \pm 6,5$ & $74 \pm 6,7$ & $83 \pm 6,1$ & $<0,05$ \\
\hline Intensity of pain, points & $49 \pm 3,6$ & $59 \pm 4,4$ & $76 \pm 6,1$ & $80 \pm 8,0$ & $<0,05$ \\
\hline General state of health & $56 \pm 6,5$ & $58 \pm 5,9$ & $75 \pm 6,1$ & $84 \pm 9,5$ & $<0,05$ \\
\hline 2. Psychological component of health, points & $47 \pm 4,8$ & $63 \pm 5,3$ & $72 \pm 7,6$ & $86 \pm 9,9$ & $<0,05$ \\
\hline Psychic health, points & $44 \pm 5,6$ & $62 \pm 6,1$ & $77 \pm 6,4$ & $85 \pm 7,0$ & $<0,05$ \\
\hline $\begin{array}{l}\text { Role functioning, conditioned by emotional state, } \\
\text { points }\end{array}$ & $50 \pm 5,4$ & $66 \pm 6,6$ & $72 \pm 6,3$ & $89 \pm 8,5$ & $<0,05$ \\
\hline Social functioning, points & $56 \pm 4,1$ & $61 \pm 5,5$ & $78 \pm 8,5$ & $90 \pm 8,6$ & $<0,05$ \\
\hline Life activity, points & $44 \pm 4,8$ & $59 \pm 5,1$ & $79 \pm 6,3$ & $81 \pm 7,7$ & $<0,05$ \\
\hline
\end{tabular}

Notes: $\mathrm{x} \pm \mathrm{m},(\mathrm{x}-$ mean arithmetic, $\mathrm{m}-$ standard error of mean arithmetic) 


\section{Discussion}

Many specialists note that physical activity is directed at strengthening of human physical condition, organism's functional state and health. $[3,5,6]$. However, as on to day physical activity has not become a demand of students. Analysis of works, devoted to formation of students' physical activity $[6,7,26]$ shows that most of recommendations of scientists are not paid attention to by higher educational teachers and coaches. In our opinion the reasons are as follows:

1) Intensive engagement of students (academic, scientific, social). Not formed motives and demands in targeted and regular physical activity;

2) Low professional-pedagogic level of teachers, who, by a number of reasons, do not see potential of students' physical activity and not overstep the frames of "Physical culture" discipline. For increasing of organism's functional potentials, physical fitness and health strengthening discipline "Physical culture" is not sufficient;

3) Insufficient material-technical provisioning of training sites;

4) Insufficient financing of students' physical culture and sports.

The received results proved that the worked our technology of physical activity influences on increasing of HEE students' life quality. In our opinion the researches of such kind it is necessary to regard:

1) As substantiation of new modern technologies, built on the base of innovative and information approaches;

2) As substantiation of physical activity technologies and their influence on life quality in main, special and preparatory groups;

3) Objects of physical activity's influence studying shall be all subjects of educational process (students and teachers).

\section{Conclusions}

1. The worked out technology of physical activity influences on students' individual health by all indicators: organism's functional reserves, physical workability, physical fitness, way of life and organism's resistance.

2. Technology of physical activity is a factor, facilitating rising of HEE students' life quality: physical and psychological components of health.

3 . It is necessary to note that as a result of application of required physical activity means with usage of intensive physical loads in experimental group we found expressed positive changes.

\section{Acknowledgements}

The study has been fulfilled in compliance with governmental task (Number 27.5769.2017/8.9).

\section{Conflict of interests}

The authors declare that there is no conflict of interests.

12.Samsonenko IV. Increase of students' life quality with application of athletic gymnastic and information technologies. Cand. Diss. Khabarovsk; 2011. (in Russian)

13.Iermakov SS, Arziutov GN, Jagiello W. Quick training of students to judo techniques. Archives of Budo. 2016;12:1524.

14.Iermakov SS, Podrigalo LV, Jagiello W. Hand-grip strength as an indicator for predicting the success in martial arts athletes. Archives of Budo. 2016;12:179-86.

15.Osipov AY, Kudryavtsev MD, Kramida IE, Iermakov SS, Kuzmin VA, Sidorov LK. Modern methodic of power cardio training in students' physical education. Physical Education of Students. 2016;20(6):34-9. doi:10.15561/20755279.2016.0604

16.Skurikhina NV, Kudryavtsev MD, Kuzmin VA, Iermakov SS. Fitness yoga as modern technology of special health groups' girl students' psycho-physical condition and psychosocial health strengthening. Physical Education of Students. 2016;20(2):24-31. doi:10.15561/20755279.2016.0204

17.Kudryavtsev MD, Kramida IE, Kuzmin VA, Iermakov SS, Cieslicka M, Stankiewicz B. Influence of study in hee on ubiquity and strength of students' computer gambling. Physical Education of Students. 2016;20(3):13-22. doi:10.15561/20755279.2016.0302

18.Drogomeretsky VV, Kopeikina EN, Kondakov VL, Iermakov SS. Adaptation of Ruffier's test for assessment of heart workability of students with health problems. Pedagogics, psychology, medical-biological problems of physical training and sports, 2017; 21(1): 4-10. doi:10.15561/18189172.2017.0101

19.Kudryavtsev MD, Kramida IE, Iermakov SS, Osipov AYu. Development dynamic of healthy life 
style personality component in relatively healthy students. Physical education of students, 2016; 20(6): 26-33. doi:10.15561/20755279.2016.0603

20.Podrigalo LV, Iermakov SS, Jagiełło W. Special indices of body composition as a criterion of somatic development of martial arts practitioners. Arch Budo Sci Martial Art Extreme Sport 2017; 13: 5-12

21.Orinchuka VA. Pedagogic conditions of students' life quality formation. Cand. Diss. Nizhny Novgorod; 2009. (in Russian)

22.Sviridova IA. Medical-social determinants of students' life quality formation. Cand. Diss. Moscow; 2011. (in Russian)

23.Leifa AV, Perel'man IuM, Shvecov MIu. Life quality, health and physical activity of Far East and Transbaikalia students. Blagoveshchensk - Chita; 2010. (in Russian)

24.Leyfa AV. The social basis of the development of physical activity of students in terms of their quality of life. Physical education of students, 2013; 17(3): 35-41. doi:10.6084/ m9.figshare. 662600

25.Aaronson N, Alonso J, Burnam A, Lohr KN, Patrick DL, Perrin E, Stein RE. Assessing health status and quality-oflife instruments: attributes and review criteria. Qual Life Res. 2002;11(3):193-205.

26.Harris J. Physical education teacher education students' knowledge, perceptions and experiences of promoting healthy, active lifestyles in secondary schools. Physical Education and Sport Pedagogy. 2014;19(5):466-480. doi:1 0.1080/17408989.2013.769506

27.Wanson SM, Keith KD. Comparing the Quality of school-age children with and without disabilities. Ment. 2002;40(4):304312.

28.Chen JY, Xiang HJ, Jiang PP, Yu L, Jing Y, Li F, et al. The Role of Healthy Lifestyle in the Implementation of Regressing
Suboptimal Health Status among College Students in China: A Nested Case-Control Study. International Journal of Environmental Research and Public Health. 2017;14(3).

29.Dore I, O’Loughlin JL, Beauchamp G, Martineau M, Fournier L. Volume and social context of physical activity in association with mental health, anxiety and depression among youth. Preventive Medicine. 2016;91:344-50.

30.Flueckiger L, Lieb R, Meyer AH, Witthauer C, Mata J. The Importance of Physical Activity and Sleep for Affect on Stressful Days: Two Intensive Longitudinal Studies. Emotion. 2016;16(4):488-97.

31.Sharp P, Caperchione C. The effects of a pedometer-based intervention on first-year university students: A randomized control trial. J Am Coll Health. 2016;64(8):630-8.

32.Khudolii OM, Ivashchenko OV, Iermakov SS, Rumba OG. Computer simulation of Junior gymnasts' training process. Science of Gymnastics Journal, 2016;8(3):215-228.

33. Reza GH, Behnam HA, Ozra E, Abbas K. The relation between service quality of sports camps and elite athletes' satisfaction of the national teams' freestyle \& greco-roman wrestling. Pedagogics Psychology Medical-Biological Problems of Physical Training and Sports. 2016;20(4):50-8.

34.Belov VI. Correction of adult population's health by means of complex physical training. Dokt. Diss. Moscow; 1996. (in Russian)

35. Ware JE, Sherburn CD. The MOS 36-item short-form health survey (SF-36). Conceptual framework and item selection. Med. Care. 1992;30:437-483.

36.Deductor: Analytical program. Ryazan: BaseGroup; 1999. [Internet]. 1999 [updated 2017 May 10; cited 2017 May10]. Available from: http:// www.basegroup.ru

\section{Information about the authors:}

Leifa A.V.; http://orcid.org/0000-0003-3453-8370; Aleifa@mail.ru; Amur State University; Ignatievskoe Highway str., 21. Blagoveshchensk, 675028, Russia.

Zheleznyak Y.D.; http://orcid.org/0000-0003-1353-5314; fakul-fk@mgou.ru; Moscow State Regional University; Radio str., 10A, Moscow, 105005, Russia.

Cite this article as: Leifa AV, Zheleznyak YD. Influence of physical activity on students' life quality. Physical education of students, 2017;21(5):244-248. doi:10.15561/20755279.2017.0507

The electronic version of this article is the complete one and can be found online at: http://www.sportedu.org.ua/index.php/PES/issue/archive

This is an Open Access article distributed under the terms of the Creative Commons Attribution License, which permits unrestricted use, distribution, and reproduction in any medium, provided the original work is properly cited (http://creativecommons.org/licenses/by/4.0/deed.en).

Received: 10.06.2017

Accepted: 25.07.2017; Published: 09.09.2017 